\title{
Reconocimiento Crítico de César Vallejo
}

\section{REMINISCENCIAS PERSONALES}

Vengo a este symposium* para traer mi testimonio (como gusta decir Juan Larrea), sobre César Vallejo. Vengo aquí para dar fe (empleando otra de las expresiones bíblico-notariales del mismo) de mi "reconocimiento" ante la poesía del autor de España, aparta de mí este cáliz. Digo "reconocimiento" no sólo en el sentido de homenaje, sino en el de "reencuentro" y nuevo examen, puesto que en la década del 20 tuve la percepción inolvidable del hombre y de la obra, hiciéralo o no público entonces, ya que ningún clamoreo era necesario ante la sencilla verdad de uno y otra.

He aquí, pues - por lo que pueda valer, agregando rasgos a la fisonomía de César Vallejo, a lo que fue su atmósfera vital-, el testimonio prometido. ¿Cuándo conocí al autor de Trilce?? Fue en la primavera parisina de 1926. Frecuentaba yo entonces a varios poetas hispanoamericanos en París, entre otros, el guatemalteco Cardoza y Aragón; el dominicano Hernández Franco. En manos de alguno de ellos había yo visto un ejemplar de Trilce, hallazgo excepcional, puesto que el autor cuidó más bien de ocultar los ejemplares que de hacerlos llegar en Madrid a las pocas revistas y personas que allí nos interesábamos por las nuevas expresiones de la poesía hispanoamericana. Aquí tenemos ya un primer razgo para la caracterización de Vallejo y su mundo: al pronto se esquivaba, erigía piedras andinas ante las miradas del prójimo. Reflejamente, mi inicial sen-

* Celebrado en la Facultad de Filosofía y Humanidades de la Universidad de Córdoba, Argentina, del 12 al 15 de agosto de 1959. 
sación ante Trilce fue la de hallarme ante un muro opaco; las hendiduras, las posibles brechas de acceso o penetración no eran perceptibles al primer contacto; tampoco mediante el asedio cauteloso. Era menester atisbar la revelación, algún paso de luz, como el que se abre hacia las páginas finales del libro, para entrar en la prisión de Vallejo, en la cárcel real donde había estado, en la cátcel de símbolos donde seguía recluso; no por supuesto, una Cárcel de amor como la cuatrocentista de Diego de San Pedro, ni tampoco transparente como la del Arcipreste de Hita, sino una cárcel de dolor y desintegración, donde su sensibilidad se daba de cabezazos contra los muros y su canto se desarticulaba en malestar ontológico y protesta cósmica. ¿Amargura, humor negro, misterio indígena? Todo eso y algo más, a través (o sin llegar a atravesarla) de una elocución abrupta, de un tejido verbal que se negaba a ser retórico, sin pretender tampoco convertirse en sistema antiliterario.

¿Era posible entonces, por aquellos días, ver más claro en él? ¿La persona agregaba interlíneas a la obra? "¿Por dónde anda Vallejo?", pregunté a los amigos antes nombrados. "Está aquí en París", me dijo Hernández Franco. "Pues vamos a verle". Y fue así como una tarde subí a un piso de la Avenue de l'Opera a cierto Bureau des Grands Journaux Ibero-Américains. ¿Qué era aquella oficina de título tan pomposo, $\tan$ rastacuero? Cierto tinglado urdido con otros fines; su "armador": Manuel Bueno, curioso tránsfuga de los albores de la generación de 1898 , quien despeñado por su epicureísmo y echando por la borda todos los escrúpulos, había sonsacado unos miles de francos al entonces dictador de España, Primo de Rivera, con el propósito de repartir algunos entre los periódicos de París y contrarrestar así las campañas que se hacían contra su desgobierno. Pero no le dirijamos ningún cargo retrospectivo, puesto que con tal empresa Manuel Bueno (no el "mártir" por supuesto de la novela de Unamu. no, sino el periodista, que llamaremos epicúreo, de tal nombre) había dado un modo de vivir a algunos escritores españoles e hispanoamericanos, remediando durante algún tiempo la impecuniosidad crónica del peruano Vallejo.

¿Cómo era el hombre? Difícil es restituir rasgos veraces a distancia, cuando tantos rostros y días y ciudades se superponen en el recuerdo de quien ha atravesado ya muchos. Había en Vallejo esa "inocencia candorosa" que ha visto bien Latrea, pero oculta tras una máscara algo dura: la de su "pathos" indígena, difícil en el primer momento de traspasar, llegando al trasfondo puro, más allá del mestizaje sufrido. "Mineraloide", 
incaico, andino - se ha dicho. Palabras de simple aproximación a su verdad natural, salvo la última, muy genérica también, pero que revela la raíz de su sustancia étnica, expresa la sacudida sísmica de cordillera que vierte la lava, el torrente desflecado de sus versos como en la juntura de un finalizar borrascoso y un recomienzo luminoso. Pero este tránsito sólo se operaría más tarde, al pasar de Trilce a los Poemas bumanos.

Larrea, "Favorable París

POEMAS" Y UN MANIFIESTO

Mas no adelantemos el reloj. Estamos todavía en r926. Pocos meses después, en el verano del mismo año, antes de emprender otro viaje, estaba yo pasando una temporada en casa de mis padres, en un pueblo manchego, desinteresado del contorno (puesto que ni la más remota sombra quijotesca era ya perceptible) y atento únicamente a las nuevas del mundo exterior. Fue así como un día el correo me trajo una nueva revista: Favorable Paris Poemas. ¿Era exactamente, tradicionalmente, una revista lite. raria? Sí, pero su primer cuidado era el de no parecerlo. Claro que ya estaba uno habituado a los trueques. Lo literario a primera vista, lo literario sin más, era una presencia ingenua que estábamos acostumbrados a soslayar. Cuando ingenuamente se incurría en ello, hasta el azar se encargaba del disfraz, de poner el gato junto a la liebre. Por ejemplo, la cubierta ritual de la revista Grecia, que hacíamos los ultraístas en Sevilla, junto a un ánfora del más puro estilo helénico, exhibía el anuncio de un bidón de gasolina. Y algo después la primera serie de La Révolution Surréaliste se presentaba exteriormente, en contraste con su radical disconformismo interior, con el atuendo de una revista académica. Por lo tanto, ninguna extrañeza en que aquella cubierta gris, sin grabados, de sencillas letras tipográficas, con el aire de un boletín médico o una memoria de Sociedad Anónima, fuera la de Favorable Paris Poemas.

Reencontré en sus páginas a Vallejo, reconocí a Larrea, el compañero de las primeras revistas ultraístas, a quien sólo había entrevisto de soslayo, algo oculto en su persona o viajero siempre, cuya presencia se me había acusado a través de Huidobro y de Gerardo Diego, su maestro y discípulo, respectivamente - dando, por supuesto, a estas calificaciones un minimo alcance temporal. (Si los señores antólogos hubieran sido más generosos, si los cronistas, ya que no historiólogos, de la promoción llegada inmediatamente después, no hubieran practicado una política tan exclusivista, los 
lectores de hoy tendrían una perspectiva menos borrosa de tal período; en cualquier caso, es sensible que Larrea no haya recogido sus poemas de entonces). Consecuente con este sino escapista, con este signo zahareño, advertí que Larrea, y ahora también Vallejo, no buscaban otras companías. Unicamente solicitaban - según decía una tarjeta adjunta- "la más resuelta hostilidad de los discrepantes". Y yo no era tal. ¿Coincidente? Tampoco exactamente. Era la suya una actitud muy personal para ser compartida. Pero en cualquier $\mathrm{CasO}_{2}$ y por lo que se refiere a Vallejo, su participación en tal revista (no por efímera, pues sólo alcanzó dos números, menos expresiva de un período renovador) viene a demostrar -contra lo que se ha escrito después- que al poeta peruano - aun reconociendo su singularidad, pero con el propósito de otorgarle una unicidad radical, más aún, de convertirle en un absoluto- no puede excluírsele de toda relación con los movimientos y tendencias vanguardistas de entre las dos guerras. No se repara en que por el simple hecho de residir en París, desde 1923, no pudo ignorarlas; a través de Larrea conoció el ultraísmo, y por otros caminos, no dejó de experimentar el contragolpe del superrealismo en su derivación marxista.

Quizá más que las poesías insertas en Favorable Paris Poemas me interesó una especie de manifiesto suscrito por Larrea y titulado "Presupuesto vital". Lo cerraba una frase que me llamó la atención. Era esta: "Nuestra literatura no es ni literatura; es pasión y vitavirilidad por los cuatro costados". Ya estábamos, pues, en el umbral de la literatura antiliteraria, de la literatura que, por expiar culpas ajenas o buscar su trascendencia en otros mundos, se avergüenza de su nombre y quiere dejar de serlo; en suma, ya estábamos a las puertas de las crisis cuyo proceso yo he intentado analizar minuciosamente en mi Problemática de la literatura. Además, no se olvide que entonces comenzaba a abrirse paso, si no a vulgarizarse, el afán de disociar la poesía de la literatura, adscribiendo a la primera todas las excelencias y a la segunda todas las abominaciones. Reparto que por su ahistoricismo evidente (amnesia y revolucionarismo total suelen hermanarse) y su caprichosidad díscola tanto había de exaltar a los poetas, permitiéndoles identificarse sin más con la Vida (así, mayusculizada) y convirtiéndoles súbitamente en héroes de su possía. La apelación a la videncia, el hechizo ante la "revelación", la apología de lo sobrenatural o extrarracional experimentada por los poetas de la década del 20 , particularmente en la lírica francesa (a raiz de la canonización de Rim. 
baud y la divinización de Lautréamont) pero con reflejos en otras literaturas, marcan el momento más alto de tal proceso.

Ahora bien, en aquel manifiesto estos afanes no se formulaban con tal articulación conceptual; se embozaban en volutas verbales y meandros simbólicos de más difícil recorrido. Tampoco se presentaban como dogmas agresivos. De suerte que la actitud de Larrea - y por ende, la de Vallejomás bien suscitaba concordancias que discrepancias. Además, había en aquel pequeño manifiesto una sintaxis, un estilo elusivo que intrigaba. Algo - en lo teórico - semejante -en lo lírico-a aquella prosa "Santa Lucía y San Lázaro" de Federico García Lorca que yo había leído, en pruebas de la Revista de Occidente, yendo en tren con su autor, pocos meses antes, a Valladolid que me había dejado fascinado.

Y no extrañe - advierto al llegar a este punto- que al proponerme evocar a Vallejo y su poesía hable tanto de Larrea, lo superponga y mezcle en mis recuerdos. Pero yo pienso que esa es una condición de su personalidad. Hasta hace pocos años - hasta la gran revelación pública de Rendición de espiritu-- nos ha sido difícil verle directamente a él mismo. Siem. pre se nos aparecía indirectamente, por interpósita persona: primero a través de su compañero de estudios, Gerardo Diego; después a través de Vicente Huidrobo, de León Felipe; últimamente, de César Vallejo. La lucidez y el entusiasmo reunidos que aplica a sus exaltados revierte sobre él, hace del apologista un apologizado. Y lo mismo probablemente pasará mañana con este otro motivo suyo de exaltación, que ya no es un poeta, ya no es un hombre, sino un hemisferio; lo mismo sucederá con este Nuevo Mundo, a cuya interpretación ha aplicado su racionalismo visionario, superando la contradicción entre ambos términos (con más rigor que André Breton; recuérdese su vivisección en Superrealismo entre Viejo y Nuevo Mundo) y forjando una hermenéutica hecha de símbolos, mitos y presagios, un sistema de claves secretas o correspondencias veladas. El mismo sistema que también ha aplicado a la poesía de César Vallejo, y que yo no dudo sea valedero (puesto que en toda poesía singular aspiramos a ver más de lo que está escrito, a penetrar el otro lado del espejo), siempre que cuidemos de no distorsionar su osatura verbal, siempre que nos atengamos a verla en sus límites; por ejemplo, a la luz del lenguaje $y$ de los problemas que engendra sobre las posibilidades y las limitaciones de la comunicación poética. Es lo que me propongo abocetar en las palabras que siguen. 
LA poesía, otro lenguaje

La poesía lírica - hoy por hoy- sigue vertiéndose en el lenguaje. Ello a despecho de algunos audaces insatisfechos que, sintiéndose apresados entre las palabras, aspiran a traspasarlas, buscando otros vehículos de expresión que van desde el signo al movimiento. Esta insatisfacción demuestra que a pesar de la "crisis del lenguaje" (que no es tal en sí misma, sino apéndice de otra crisis más general) los poetas deben seguir usando de su específico instrumento.

Ahora bien, de antiguo sabemos que - señalados "grosso modo"hay por lo menos dos grandes sectores del lenguaje: el directo y el indirecto, o expreso y simbólico, o cognoscitivo y evocativo. Según sea el grado de acercamiento o lejanía respecto al mundo de la realidad, así el lenguaje oscilará entre la nominación y la elusión, o más exactamente aún, entre lo asertivo y lo alusivo, con independencia del molde formal en que se manifieste, sea prosa o verso. Tampoco es de hoy el reconocer que la poesía es, o puede ser, un lenguaje especial - como el de la filosofía o el de la matemática-; pero eso no basta. Más explícito es calificar la poesía como otro lenguaje, siempre que no se quede en lo formal, siempre que junto a la peculiaridad del continente agregue la sustancia del contenido, Pero ¿cómo definirlo, cómo reconocerlo? En principio, por su aproximación al prelenguaje primitivo, desde el momento (explica W. M. Urban, Lenguaje y realidad) en que la representación poética tiene un carácter no analógico, sino metafórico.

Yo recuerdo siempre cierta frase del olvidado Rémy de Gourmont (pero que ha recordado alguna vez Jean Paulhan), cuando decía que "en el estado actual de las lenguas europeas casi todas las palabras son metá. foras". Es decir, que aunque sucumbamos al habla usadera, nos manejamos cotidianamente, sobre todo en el habla afectiva, con palabras que son designaciones de designaciones, con frases transpuestas. Cuando no vigilamos mentalmente nuestra habla, cuando nos dejamos llevar por la corriente tradicional del idioma, por los refranes y las frases hechas, cuando nos creemos rebajados al más llano prosaísmo, sucede paradójicamente que poetizamos a mansalva. Vista así, con perspectiva historicolingüística, la moneda corriente, los discos manidos de las expresiones proverbiales se truecan en soles nuevos, recién acuñados, reverberantes. No es, pues, exacto, contra lo que afirma Jean-Paul Sartre (¿Qué es la literatura?), que los poetas sean los seres que se niegan a utilizar el lenguaje. Más lo es afirmar 
que "el poeta crea el mito del hombre, mientras que el prosista traza su retrato"; siempre que no se alce un tabique divisorio falazmente genérico entre "poesía" y "prosa" y traslademos a nuestro idioma el sentido más amplio que encierra la palabra Dicbtung. Siempre asimismo que el poeta, al preferir el lenguaje gratuito al funcional, acierte a usar del primero como un "engaño a la vista", sin pretender darle una trascendencia que no tiene, aceptando su fatal inmanentismo.

Bajo la apariencia de beneficiarla, yo entiendo que han hecho mucho daño a la poesía las sublimaciones de un Novalis y un Hölderlin y sobre todo los deliquios que de ellas ha extraído Heidegger. Además, si se ha subrayado con exceso el papel atribuido a la "palabra poética", si se ha insistido hasta la saciedad en que "el ser del hombre tiene su fundamento en el lenguaje", no se ha reparado suficientemente en que éste "sólo alcanza una realidad histórica auténtica en el diálogo". ¿Y qué otra cosa sino la comunicación presupone este diálogo? De suerte que sin comunicación no hay poesía; todo se reduce a un solipsismo, curioso como experimento, pero intransferible, estéril. El presunto y grandioso "mensaje" que permanece inexpresado, que no llega a articularse de forma transmisible, es una impostura; y como además suele suceder que está despro. visto de todo encanto verbal, ni siquiera alcanza la irreal realidad de un juguete, del gracioso "aboli bibelot d'inanité sonore", mentefacturado por Mallarmé. La lección del autor de Un coup de dès no debiera haber sido olvidada. Aun admirándola, parece desprovista de todo sentido repetir su imposible hazaña, que es el "fracaso del lenguaje frente a lo absoluto" (según su último intérprete, Hans Friedrich, Estructura de la lírica moderna), para volver a encontrarse con la misma "nada", aunque su hueco, mediante un espejismo, parezca ahora a algunos llenos de tesoros inexplorados.

Con todo, si por el camino que llamaríamos patético, el laberinto no tiene salida, ya que no hay una Ariadna entre el boscaje, por vía irónica o humorística el experimento no ha dejado de repetirse. Así el que hace aproximadamente un cuarto de siglo, a la zaga de James Joyce, realizaron los inventores de Vertigral o el "lenguaje de la noche", y cuyas únicas consecuencias perdurables han sido las distorsiones vocabulares de un Henri Michaux y de un E. E. Cummings. Con la diferencia de que mientras el autor del Voyage en Grande Carabagne inventa no sólo palabras, sino países habitados por una extraña fauna, el autor de Tullips and Cbimneys se pierde voluntariamente en lo ininteligible y sus distorsiones del lenguaje 
(como resume R. P. Blackmur, Form and Value in Modern Poetry), tomadas solemnemente, sólo parecen una especie de "baby-talk". Continuando, atenuando más bien, la línea del primero, damos con las cabriolas joculares allende su intención social subversiva, de un Jacques Prévert o un Raymond Queneau; prolongando la línea de E. E. Cummings, la serpiente se muerde la cola y torna a la esfinge bicéfala de Mallarmé-Joyce. La otra meta ambicionada y que representa el llamado "grado cero de la escritura", en que "el objeto quiere libertarse del lenguaje" (según expresión de Gaëtan Picon), se pierde en un punto insasible, sin confines especiales.

\section{SÍMBOLOS Y SIGNOS}

Por el momento, pues, más fértiles parecen ser otras vías que se abren al conocimiento $d e$ la poesía (ya que no al conocimiento por la poesía), al menos, más específicamente literarios: la exploración de las po. sibilidades del lenguaje simbólico y sus signos, de la semántica y la semiótica. No es así extraño que, paralelamente al reconocimiento de la poesía como otro lenguaje - al menos potencial, balbuciente- hayan surgido, en estas últimas décadas, numerosos estudios sobre los problemas del lenguaje, vistos desde el lado filosófico, pero con derivaciones implícitas hacia el campo estético. Quizá su punto de partida se halla en Ernst Cassiser, con su concepción del hombre como "animal simbólico"; idea que Suzanne K. Langer (Clave para una nueva filosofía) explota y amplía convirtiendo en símbolos los datos de los sentidos. Que el lenguaje influye sobre el pensamiento, y no al revés, constituye a la vez el origen de las especulaciones, más curiosas que convincentes, de C. K. Ogden e I. A. Richards (El significado del significado); por su parte, Charles Morris (Signs, Language and Behaviour) ve al hombre como un ser perdido en un universo de símbolos y asimila cada uno de ellos a determinada clase de comportamiento. Pero volviendo al campo específicamente literario (en el que no debe olvidar incluirse al citado I. A. Richards por sus Principles of literary criticism - donde desarrolla la tesis de que el mundo de la poesía no tiene ninguna realidad diferente del resto del mundo y que debe ser sometido a las mismas leyes de interpretación psicológica-, libro que tanta influencia ha ejercido en el "New Criticism" norteamericano), más nos importan otros testimonios en relación con la crisis del lenguaje.

Allen Tate llega hasta sostener que "la deterioración del mundo contemporáneo debe ser estudiada a la luz de la deterioración de su lenguaje". Nada más exacto. La enfermedad de las palabras - trocadas de sentido, 
desfiguradas, falazmente empleadas - no es sino un síntoma de la enfermedad de las conciencias. Quizá por ello mas no con fines apologéticos, como pudiera parecer, sino todo lo contratio, Roland Barthes (Mytbologie $d u$ language') ha llegado a escribir que la "poesía contemporánea es un sistema semiológico regresivo". "Mientras que el mito - añade- tiende a ser una ultrasignificación, la poesia tiende a reencontrar una infrasignificación, un estado presemiológico del lenguaje; en suma, se esfucrza por transformar el signo en sentido y se afirma como un asesinato del lenguaje". De tal forma, apostillemos con la debida ironía, en vez de alzarse con el botín de la literatura se habrá limitado a estrangular la gallina de los huevos de oro. Pero en este punto, puesto que hasta la fecha el instrumento verbal con que tales teorias se propagan, aunque no intacto, sigue bastante usadero (ya que el arma con qué asesinar al lenguaje, el metalenguaje, aún no existe), todos los delirios imaginativos son permisibles.

Que hay un misterio en el lenguaje es incuestionable. Lo hubo en el alba de todas las lenguas; se replantea en su crepúsculo. Como al hombre primitivo, nos acomete a veces la perplejidad del porqué de la concordancia o discordancia entre los sonidos y sus representaciones; más aún, entre las designaciones presuntamente directas de ideas $\mathrm{u}$ objetos y las figuradas, es decir, el salto semántico, el trueque o metamorfosis que termina en metáfora. Pero ¿acaso especular, tanto imaginativa o científicamente, sobre los enigmas del idioma, no será atentar contra la integridad del cosmos, no equivaldrá a una autodestrucción, a condenarse al silencio? Por algo quien ha estrechado más el cerco de la cuestión, Ludwig Witgenstein (Tractatus logicophilosopbicus), sentencia: "Sobre lo que no se puede hablar más vale callar", o como ha escrito José Ferrater Mora (Cuestiones disputadas): "discutir sobre lenguajes y metalenguajes es entretenido; es también impertinente. Intentar descubrir un lenguaje ideal es meritorio; es también inútil".

\section{La poesía de Vallejo a}

LA LUZ DEL LENGUAJE

Sin embargo, manteniendo la cordura, en el caso de César Vallejo no es impertinente, antes al contrario, puede resultar más provechoso que buscar en su poesía profetismos o revelaciones metafísicas, encararla a una luz que le es más propia, la del lenguaje. Pero no en la dirección es. 
tilística, como algunos por moda o perezosamente - empero la paciencia inútil que reclama tal método- se inclinarían a creer, no. Su última clave de comprensión se halla muy estrechamente ligada con la semántica y la simbología. Con la primera porque buena parte del material léxico que Vallejo utiliza - tanto en Trilce como en Poemas bumanos, aunque más acusadamente en el primer libro-, es alógico; casi todas las palabras que arroja con aparente iracundia, pero sencillo candor, están voluntariamente desquiciadas. Se nos presentan, en efecto, como salidas de su quicio natural, y aun las oraciones más completas parecen fragmentos desprendidos de un contexto cuyo sentido total apenas queda explícito, si no es con el auxilio de la conjetura o la adivinación.

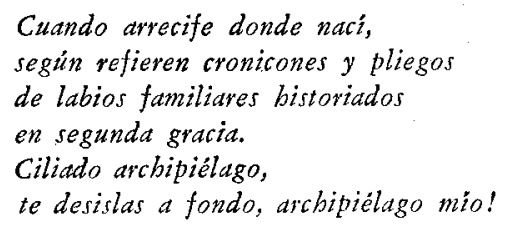

(Trilce, XLVII)

¿Se trata de una escisión absoluta entre el "significado" y el "significante" - por emplear las expresiones de Saussure que ha divulgado Dámaso Alonso, con prevalencia de este último? Quizá no exactamente, pues desde el momento en que el poeta desdeña todos los halagos rítmicos, eufónico, aquí no hay imágenes acústicas que reemplacen el significado conceptual. La ruptura con el sentido, la incursión en el sinsentido poético se efectúa preferentemente mediante la disociación de la trama sintáctica, más particularmente, mediante algunos trueques adjetivales donde Vallejo refleja sus sacudidas internas.

Quiero escribir, pero me sale espuma,
quiero decir muchisimo y me atollo;
no bay cifra bablada que no sed sumat,
no bay piramide escrita sin cogollo.

De ahí deriva probablemente su propensión al desdoblamiento, al verse a sí mismo como un otro, operación de tan notorio linaje rimbaudiano ("Yo es otro") que reecontramos frecuentemente, con distintas proyecciones, en la filosofía y en la lírica de estos últimos años: el problematismo del yo y del tú (Buber, Jaspers, Sartre); el "otro que va 
contigo" (buscado en el espejo por Antonio Machado...); el otro del drama unamuniano del mismo título.

Un hombre pasa con un pan al bombro. ¿Voy a escribir después sobre mi doble?

A lo mejor, soy otro: andador, al alba, otno que marcba en torno a un disco largo, a un disco elástico: mortal, figurativo, audaz diafragma.

(Poemas bumanos)

Inclusive, a veces, descorriendo la cortina, el poeta se identifica, o se disocia, con su otro, nombrándose a sí mismo. Recuérdese sólo el comienzo de "Voy a hablar con la esperanza": "Yo no sufro este dolor como César Vallejo. Yo no me duelo ahora como artista, como hombre, ni como simple ser vivo siquiera...". Para Juan Larrea (César Vallejo o Hispanoamérica en la cruz de su razón), este desdoblamiento de Vallejo significa que "estamos en el campo del arte-vida, de manera que el héroe manifiesta serlo de otra especie".

\section{Equinalencias en La Plástica}

También con la simbología, y más aún, con la semiótica o teoría de los signos, se enlaza la poesía de César Vallejo, y vista bajo su foco puede of recer todavía nuevas reverberaciones. Si la imagen se sustenta sobre las posibilidades incalculables que of rece la ampliación, la multi. plicación traslaticia de las palabras, el concepto cuenta con el recurso de los signos como primera y última y más elaborada expresión. Si aceptamos - al menos momentáneamente- que la poesía pueda ser revelación de lo prístino, transmisión de lo inconsciente colectivo, convendremos que su sentido último -a la vuelta de muchas exploraciones sobre su misterio- es el originario. Es decir, un sentido sin sentido conceptual, un sentido simbólico no figurativo: el mismo que el de los cantos más remotos, el de las cantilenas o los conjuros con algo de arenga o de exorcización. Así se explica que el flujo subconsciente y la irracionalidad voluntaria, cuando se conjugan con fines deliberadamente antiliterarios, renuncien a los morfemas y desemboquen en los puros fonemas sin sentido, en las onomatopeyas y las agrupaciones vocálicas. Muy varios son 
los ejemplos que pudiéramos aducir en la poesía de estas úitimas décadas, desde las "palabras en libertad" hasta los cantos negroides, sin olvidar caprichos unipersonales como los del letrismo y las jitanjáforas.

Algo semejante nos habia adelantado ya la comprobación del mismo fenómeno en el mundo de la plástica. Desde Picasso — desde el momento de las anamorfosis picassianas-- hasta la fecha, la pintura y la escultura tienden manifiestamente a hacerse signos. Reflejan realidades no aprehensibles visualmente en nuestro alrededor; estilizan no los objetos mismos, sino los símbolos de los objetos que percibimos. ¿Y qué decir de la mezcla de elementalismo infantilizado y de rusticidad muy elaborada que traducen los cuadros y composiciones de Joan Miró? Así como el cubismo nos daba no las formas sino las metáforas de las formas, así "en Miró los signos son símbolos de las metáforas, metáforas en su grado enésimo" (según escribí en "Joan Miró o la fuerza del signo", Papeles de Son Armadans, Palma de Mallorca, número XXI, XII, 1957). En suma, esta plástica es todo lo contrario del arte de primer grado o convencional, tanto como del "art d'aprés 1 'art"; pudiéramos decir que es un arte contra el arte, un arte de segundo grado, en un sentido puramente ordinal —entiéndase bien - y no el de la calidad.

En la misma calificación pudiera entrar la poesía moderna que exige al lenguaje —según ha escrito atinadamente Hugo Friedrich - la doble y paradójica función de expresar y a la vez encubrir un significado. De ahí deriva su fatal oscuridad, el difícil equilibrio a que está obligada y en que muy pocos saben mantenerse, despeñándose con frecuencia en la gratuidad y el absurdo sin remisión. Las fronteras de la libertad potencial del poeta son más limitadas que las del artista plástico, desde el momento en que su vehículo expresivo, la palabra, está sujeta a una fiscalización que no tiene la línea. Mientras que un grafismo caprichoso, un arabesco inexpresivo puede defenderse por el ritmo que cobre en un conjunto, ningún morfema se sostiene sin articularse de modo inteligible en un período. La impostura es vituperable en ambos casos, pero en la lírica se me antoja más grave, puesto que constituye un atentado contra la esencia del logos, merced al cual existimos como juncos pensantes.

\section{Rebelón Lingüística y Superación del Hermetismo}

No creo que en la poesía de Vallejo, aun reconocida su imparidad señera, todo sean aciertos, pues su. vida azacanada y breve le impidió depurarla, reverla a distancia o con cierta objetividad; tampoco estimo 
que ni a la luz de los análisis más finos -y ya cuenta con algunos de calidad- puedan explicarse satisfactoriamente todas sus oscuridades $y$ disociaciones. Sin embargo, quede aquí apuntada, en la misma dirección lingüística, otra posible pista. Sabido es que el autor de Heraldos negros, antes que un subvertidor literario fue un rebelde social. ¿Por qué se rebela, pues, contemporáneamente a sus días iniciales de Santiago del Cauco, no sólo contra la sociedad, mas también contra el lenguaje? Sin duda por el mismo motivo que un Maiakovsky tuvo para sumarse a una revolución que, en sus últimas consecuencias, le era hostil; por la misma razón que Jean.Paul Sartre (L'bomme contre les cboses) ha señalado en otro poeta singular, en Francis Ponge: "Lo que éste reprocha al lenguaje es, ante todo, ser el reflejo de una organización social que execra".

Ahora bien, en Vallejo la protesta era pura, desinteresada. Si momentáneamente sirvió o quiso servir a una idea (más bien, un dogma), nunca se sirvió de ella. A diferencia de otros, minuciosos, voraces aprovechadores, Vallejo, en cuanto poeta, en cuanto hombre de letras, nunca se apoyó en ninguna plataforma extraliteraria, política; su único sostén estuvo en sí mismo. Si fue a Rusia en dos ocasiones, lo hizo a sus expensas; el libro-reportaje que escribió, más allá de una simpatía apriorística, no rebasa los límites de la objetividad. Cierta arisquez temperamental, cierto libertarismo ingénito le hicieron inmune probablemente a todo enrolamiento sectario.

Vallejo, al entrar en su sazón, momento que lamentablemente ante. cede en poco al de su temprana muerte, hace a un lado todo solipsismo, extiende el radio de su mensaje, intuyendo que cualquier hermetismo voluntario es una vía muerta y que toda poesía de altos niveles es inevitablemente, no puede dejar de ser nunca, irradiante, transmisible. Esto, por supuesto, sin que el poeta haya de renunciar a la forja de su instrumento verbal, pero al mismo tiempo proporcionando claves unívocas de sus signos lingǘrsticos. "Afirmación esta última que no contradice lo que antes expresé respecto al lenguaje propio de la poesía; antes al contrario, la confirma, pues, según lo encuentro muy bien expresado por un grupo de poetas actuales (conclusiones del Segundo Congreso Internacional de Poesía, Knokke, Poésie et langage), si el lenguaje hace el poema, no es todo el poema. Es - dicen-un instrumento, un modo de comunicación, pero no un fin ni su esencia". También me solidarizo con otra expresión de los mismos, no por obvia menos pertinente: "La poesía, función humana, no tiene otra misión que expresar al hombre en sus reacciones más 
sensibles y más profundas. Una poesía fuera de la órbita humana, fuera del ritmo humano, está condenada a desecarse".

Aunque sólo fuera por la posesión de esta virtud humana — no abs. tracta, sino adecuada a un tiempo, condicionada por unas circunstancias históricas determinadas-, la poesía de César Vallejo está destinada a vivir, crecer, a influir. ¿Cuál otra, si no ésa, es la razón, el secreto del enhechizamiento que ejerce sobre las últimas generaciones americanas? En su desasosiego profundo, en su red de contradicciones, en el malestar psíquico que trasunta se reconocen a sí mismas como proyectadas sobre un espejo quebrado, pero fiel.

\section{Nuevas Claves: Americanismo, Barroquismo}

Encarada así la poesía Vallejiana, ¿dónde quedan, a dónde van a parar ciertas especulaciones que se han aventurado no ya sobre sus consecuencias sino sobre sus precedencias? Aludo a quienes le adjudican un linaje mallarmeano, olvidando o poniendo en segundo término sus verdaderos cimientos: el heredado temblor andino, la profunda conmoción telúrica de su raíz nativa $y$, finalmente, su abolengo barroco. He ahí, conjugadas, las principales líneas generalógicas que determinan el perfil más singular del poeta $y$ en que hasta ahora no se ha reparado de modo suficiente. Éstas y no otras, a mi parecer, constituyen su más veraz "background", nos dan al trasluz la imagen auténtica de su americanismo raigal y su barroquismo subconsciente. ¿Acaso no podían más en el cholo Vallejo tales fuerzas, tal corriente hereditaria que las asimilaciones e influjos posteriores? Puestos, pues, a buscar su genealogía, yo rastrearía, en primer término, los glóbulos barrocos que fluian en su sangre. Más cerca, en lo hondo, que de cualquier totem moderno europeo está de sus compatriotas, la incógnita Amarilis y el Lunarejo; más próximo, siempre, a pesar del alejamiento físico, del Cuzco que del Montparnasse. Distinguir ahora la gradación exacta de tal barroquismo y sus alcances o ecos en la poesía vallejiana, rebasaría los límites de este ensayo. Quede, no obstante, apuntada como una incitación, para nuevos estudios, la posible fértil pista que se abre en tal dirección..

Guillermo De TORRE

Universidad de Buenos Aires

Buenos Aires, Argentina 